\title{
Ethical Praxis and The Business Case for LGBT Diversity: Political Insights from Judith Butler and Emmanuel Levinas
}

\author{
Carl Rhodes \\ University of Technology Sydney
}

Published as: Rhodes, C. (2017). Ethical Praxis and the Business Case for LGBT Diversity: Political Insights from Judith Butler and Emmanuel Levinas. Gender, Work \& Organization, 24(5): 533-546.

\begin{abstract}
This paper critically reconsiders debates about the business case for workplace diversity as exemplified in LGBT activism. These debates have long suggested that there is an oppositional distinction between justifying diversity on self-interested business grounds, and justifying it the grounds of ethics, equality and social justice. This has led to an impasse between ethically driven diversity theory and activism, and the dominant business case approach commonly deferred to in managerial practice. As a way of mediating this impasse the contribution of this paper is to demonstrate how 'ethical praxis' can be deployed both despite and because of non-ethically motivated approaches to ethics in business. Drawing on Judith Butler and Emmanuel Levinas' considerations of the relationship between ethics and the practice of justice, it is argued that critiques of the business case for diversity rely on a pure ethics that does not adequately recognize its connection to lived politics. Conversely, support for the business case evinces a politics that has failed to remember its origin in ethics. The paper positions ethical praxis as a political intervention undertaken in the name of ethics and uses this to suggest that the business case, despite its ethical poverty, holds potential to create real opportunities for justice in organizations.
\end{abstract}

Key Words: Diversity, Emmanuel Levinas, Ethics, Judith Butler, Justice, LGBT; Praxis.

\section{Introduction}

Justice and social equality for lesbian, gay, bisexual, and transgender (LGBT) people has become an issue of major contestation on the global political agenda. This is a battle where homosexuality is still a crime in many countries, where LGBT people face discrimination, harassment and violence in society, where family law applies unequally to people in nonheterosexual relationships, and where same-sex marriage is aggressively opposed by many factions of society. Nowhere has this battle been played out more strongly than in the workplace (Humphrey, 1999; Raeburn, 2004; Colgan and Rumens, 2014). In this arena LGBT people continue to experience discrimination, abuse and stigmatization $(\mathrm{Ng}$, Schweitzer and Lyones, 2012) despite activism seeking to address these issues having been in place since the 1970s. While part of a broader movement for LGBT equality, activism in the workplace has its own unique characteristics. Chief amongst these if that in order to garner organizational support, those promoting workplace equality have long been pressured to "balance their activist agendas with the need to contribute to the organization" by helping "create competitive advantage or improve organizational effectiveness" (Githens and Aragon, 2009: 124). 
The situation today is that "the proactive take-up of organizational equality and diversity activities [has been] driven by business case and bottom line arguments" (Özbilgin and Tatli, 2011: 1235). Although the business case for diversity has been advocated in management practice, it has come under severe criticism, especially on moral grounds. Indeed, critically questioning the value of 'business case' arguments is an established part of diversity studies (Zanoni et al, 2010). The resulting situation is that "tension between an approach based on utilitarian arguments (the business case) and an approach based on social justice and human rights forms a crucial point of debate in the diversity and equality field" (Tomlinson and Schwabenand, 2010: 102). This tension arises because support for the business case relies on the presumption that "being morally good is materially good for business" (Michalos, 2013: 599), while critics see it as being 'fatally flawed' because it rests on a set of motives that are not ethically driven (Cragg, 2002).

The purpose of this paper is to critically reconsider debates about the business case for diversity, with specific reference to LGBT activism. While some argue that "radical practice of diversity necessarily involves rejection of the business case" (Tomlinson and

Schwabenand, 2010: 116) the paper will explore how what will be called 'ethical praxis' can effectively operate within and against such business logic. Critiques of business case approaches rely on a consideration of the meaning of ethics as it resides in the motives of organizations. While this is an important consideration it fails to account for how the business case logic can actually be used for purposes that are different from, and possibly in contradiction with, those motives. This calls for a way of theorizing diversity politics that, instead of standing on the moral high ground, adds to its ethical position a concern with the practicalities and possibilities of praxis. Such praxis emerges from considering how theory, in this case ethical theory, might inform "methods of acting in, engaging with, and addressing concrete ethics issues" (Nielsen, 1993: 131). To be clear this paper seeks to document, explore and to some extent theorize this praxis but, emphatically, not to have invented it. The hope is to contribute to a research agenda that will highlight how diversity activists already have and can pursue workplace justice in organizations where business based justifications for organizational changes of any kind are demanded. With such an agenda it is justice that is the unfaltering goal, yet it is a manipulation and exploitation of the business case logic that can be part of the political means.

In exploring the idea of an ethical praxis for diversity, the paper begins by reviewing and problematizing the distinction between business case and social justice justifications as they have become dominant in discussions workplace diversity, including specially LGBT diversity. This distinction holds that while business approaches see diversity as just another a means for securing commercial self-interest, social justice approaches claim a genuine ethical interest beyond business justification. Second, the paper explores the specifics of LGBT diversity in terms of heteronormativity (Warner, 1993) and cisnormativity (Spencer and Capuzza, 2016) such that the identification of LGBT people as a belonging to a singular category is based on them being 'other' to the assumed norms of cisgendered heterosexuality. This is explained through Judith Butler's $(2003,2004,2005,2015)$ reading of the ethical theory of Emmanuel Levinas $(1969,1974,1985,2003)$ as it relates to the politics of de/humanization. Third, Levinas' conception of justice is explored as a means to argue that the ethics of diversity must be matched with a politics if it is to be effective. Through this, ethical praxis is identified as a means through which diversity activism can be theorized and has been practiced as an ethically informed yet pragmatic politics. Fourth, the issue of the business case for workplace diversity is reconsidered in relation to this ethical praxis so as to 
interrogate and elaborate the ethical possibilities that the business case logic inadvertently gives rise to. The paper concludes by outlining how ethical praxis is a way that both uses and resists instrumental approaches to diversity so as to break impasse between the business case and the social justice case.

\section{The Business Case for LGBT Diversity}

For contemporary corporations workforce diversity has become a major managerial and commercial concern (Herring and Henderson, 2014) heralded by a shift over the past 20 years from a focus on equality and equal opportunity to diversity management (Kirton and Greene, 2009). Central to debates on diversity has been a consideration of the motives behind why organizations have and should seek to adopt it. The debates have revolved almost exclusively around the distinction between the business case and the social justice case for diversity (Bleijenbergh, Peters and Poutsma, 2010) with the legal case sometimes added as a motivation but usually only when discussing public sector organizations (Colgan et al, 2009; Healy et al, 2011). Although activism for workplace diversity originated from social concerns about discrimination and injustice towards women and racial minorities, in its adoption in business it has taken a much more economic and commercially driven direction (Tomlinson and Schwabenland, 2010). What is referred to as the 'business case approach' is the dominant justification for diversity. It claims that a diverse workforce, at both firm and labour market levels, has direct business benefits. Hence it is for the purpose of commercial self-interest that forms of discrimination that impede diversity should be removed (Konrad, 2003).

The present situation, as initiated in the 1990s, is that "practices and discourses of diversity management have been increasingly justified by reference to business case arguments, leaving the impression that social justice concerns are less relevant" (Tatli et al, 2015: 1233). This has resulted from "a shift where market discourses of the business case replaced moral discourses of justice and tolerance" (Kamp and Hagedorn-Rasmussen, 2004: 532). One effect of this has been the depoliticization of equality and the usurpation of justice based activism with business based pragmatism (Kirton and Greene, 2009). As with practices of gender and racial diversity that preceded it, LGBT diversity has also been enrolled in this logic. The justification is that organizations with "high sexual orientation diversity [and] with a strong proactive diversity strategy" will outperform their peers (Cunningham, 2011b: 458). This view is also shared by managers who state that in relation to LGBT employees "corporate business objectives [are] the major drivers shaping diversity policy and practice" (Colgan, 2011: 731).

Benefits from diversity, it has been argued, come in the form of: cost savings through lower turnover, reduced absenteeism, fewer discrimination lawsuits, improved quality of staff, improved understanding of diverse consumers, and increased creativity (Robinson and Dechant, 1997). With specific reference to LGBT diversity, positive business outcomes also include opening up markets within LGBT communities, driving organizational culture change by including diverse perspectives, and appearing 'family friendly' by supporting same-sex parent families (Foldy and Creed, 1999). It is also suggested that promoting LGBT diversity results in reduced workplace conflict and improved job satisfaction (Sawyer et al, 2015). An organizational culture dominated by heterosexism is argued to prevent many lesbian, gay and bisexual workers from being 'out' in the workplace as well as heightening levels of discrimination; both of which can be result in role conflict, turnover and poor job satisfaction (King and Cortina, 2010). It has further been surmised that "sexual orientation diversity is positively associated with the presence of a creative work environment, and that 
this relationship is strengthened when there is a strong commitment to diversity within the organization." (Cunningham, 2011a: 1042-1043). When, in 2003, the UK outlawed discrimination based on sexual orientation, the justification for the passing of those laws included business case arguments (Colgan et al 2009).

The enthusiasm for promoting LGBT diversity to achieve commercial goals has endured significant critique (Lorbiecki and Jack, 2000; Heres and Benschop, 2010). This critique rests on the distinction between the business case approach and one that is committed primarily to addressing issues of "social justice, lack of representation, and discrimination within society and organizations" (Ahonen et al, 2014: 263). Here, social justice is seen as an ethically justified end in its own right, irrespective of commercial imperatives or effects. By implication the logic and discourse of business serve to sully the more idealistic notions of ethics, fairness and justice. Even in practice it has been argued that it is not business led initiatives that lead to improved levels of equality for LGBT employees. Instead, "impetus for sexual orientation equality work in many organisations has been the activism of LGBT people and their allies" and "based on social group membership, a social justice case and the need for collectivised action" (Colgan and McKearney, 2012: 360 and 372).

It has been postulated that "the most notorious aspect of the diversity approach is that it seeks to bring about change within organisations on the basis of the "pull' of business benefits" (Braithwaite, 2010: 147). This notoriety arises from an ethical critique of commercial selfinterest. The logic is that if diversity is adopted for business reasons, then its motives are selfish rather than arising from ethical demands for equality and justice. With business case diversity, social justice is argued to be sidelined because "the business case perspectives on diversity management often treats workforce diversity as a strategic asset based on an implicit assumption that achieving equality and social justice are not the legitimate 'business' of organizations" (Tatli et al, 2015: 1246). Moreover, the implication is that if diversity and anti-discrimination programs do not result in commercial advantages, then they are best abandoned in favour of whatever other initiatives will (Knights and Omanović, 2016). The danger of the business case approach is thus identified as leading to "regressive equality outcomes if differences are deemed relevant only when they are compatible with bottom line demands" (Özbilgin and Tatli, 2011: 1231).

The dominance of the business case argument is said to have led to a patchy and uneven application of diversity practices in organizations. This is especially so for LGBT diversity, as LGBT issues are still regarded by many as either a 'sensitive' or 'taboo' area (Colgan et al, 2009). While diversity management as a general organizational practice is well established, it remains the case that LGBT diversity is not acted upon and that research (Yang and Konrad, 2010) and organizational programs have "a predominant focus on differences emanating from people's ethnicity/race, sex and age" (Heres and Benschop, 2010: 441). If there is a business case for diversity, it seems that it applies unequally to those categorized as LGBT as compared to women and racial minorities. This difference is also noted within the generalized category of LGBT. The joining together of diverse sexualities and bodies identified under this rubric, while possible a valuable as a political alliance, obfuscates the different types and levels of discrimination that different people face. This has meant, for example, that while gay men, lesbians, and bisexuals might more easily assimilate into the business case logic, transgender people are largely ignored by diversity management (Ozturk and Tatli, 2015) while at the same time being chronically subjected to aggression, hostility, animosity and discrimination in the workplace (Sangganjanavanicha and Cavazos, 2010). Even the justice of the business case is not meted out equally. 


\section{LGBT 'Identity', Ethics, Hetero- and Cisnormativity}

LGBT diversity differs from other forms (especially gender diversity) in that its object is not a group identified in terms of a singular shared identity or set of identity characteristics, nor are LGBT people a "unified social group" (Colgan, 2016). For example, on their own terms there is little intrinsically in common between a transgender sex worker, a gay stock broker, and a non-binary teenager working at McDonald's after school. Even though the workplace challenges faced by people of different sexual orientations and identities are quite different from each other (Shore et al 2009; Chung 2003) each can be classified as being the subject of LGBT diversity. What gives people categorized as LGBT commonality resides less in a shared identity and more in a shared alterity; in what they are not. To be LGBT means to not to conform to the ideals valorized in heteronormative and cisnormative culture as they relate to sexuality and gender. With heteronormativity (Warner, 1993) the reference is to "the institutions, structures of understanding, and practical orientations that make heterosexuality seem not only coherent - that is, organized as a sexuality - but also privileged" (Warner and Berlant, 1998: 548). Heteronormativity operates at a moral level so as to define heterosexuality as being part of a culture bestowed with "rightness and normalcy" (p. 554). It is a regulatory practice embedded in law, social institutions and everyday practices (Chambers and Carver, 2008), and, traditionally, in the workplace. Heteronormativity establishes heterosexuality's political power (Chambers, 2007) through inclusion and exclusion. Cisnormativity also relates to dominant heteroseuxuality, but specifically reflects a cultural norm that assumes that "gender remains stable and also supports a gender binary, assuming there are exactly two genders, and that every person is either/or" (Spencer and Capuzza, 2016: 13). As with heteronormtivity, what is in place with cisnormativity is the powerful categorization of people in opposition to an assumed norm, and the discrimination that is enacted through that power (Bendl and Hoffman, 2015). As such, the category of LGBT, rather than having an internally consistent structure of common characteristics, identities, desires or practices, is defined as the agglomeration of various possibilities around gender, sex and desire that do not conform with hetero- and cisnormativity (Bendl, Fleischmann, and Walenta, 2008). In this sense hetero- and cis- normativity produces its LGBT other, at least on a categorical level. The social justice case for LGBT diversity thus rests on an ethically motivated resistance to these normativities in the workplaces (Rumens and Tyler, 2015; Bendl and Hoffman, 2015).

Hetero- and cisnormative exclusion and LGBT workplace activism as it relates to ethics and politics can be fruitfully understood through Judith Butler's more recent work (see Rumens and Tyler, 2015), especially as it draws on the philosophy of Emmanuel Levinas ${ }^{1}$. As Butler (2004) explains, Levinas shows how ethics is not rooted in reflexive awareness or knowledge of either one's self or of others, but rather in the self being disrupted by the other. Morality, then, "does not proceed from my autonomy or my reflexivity" (p. 130) instead it is that very sense of the self that is rendered precarious by a responsibility that comes from the other. For Levinas (1969) the very meaning of ethics resides in a primordial respect, care and reverence for the other person, where that person is regarded not as another of me, but as being unique and unassimilable into my own knowledge. Levinas offers an ethics of the other, in that rather than being based on self-love, self-comparison or self-interest it finds its original locus

\footnotetext{
${ }^{1}$ Butler's engagement with Levinas in the 2000s is not primarily related to a consideration of gender or sexuality, but rather to issues of the meaning of morality (2005), global politics (2004) and political Zionism in particular (2013). Theoretically, however, the issues Butler draws out are relevant to politics in its different manifestations, including, in this case LGBT politics.
} 
in concrete experience with the other person. This ethics is thus opposed to egotism, greed and hubris. For Levinas the ethical expression of being human rests on an "exception to selfishness, infantile narcissism, and egocentricity" (Marcus, 2015: 13) such that "the other concerns me despite myself" (Levinas, 2003: 57). This focus on alterity is clearly salient to workplace diversity in that "diversity in Levinasian terms inevitably involves the ethical acknowledgement of the Other's otherness" (Muhr, 2008: 186); the very acknowledgement precluded organizationally by hetero- and cisnormativity. For Butler, this engagement with alterity is political in that "power circumscribes the kinds of ethical encounters that take place - how existing normative frames operate to regulate and determine who counts (and who doesn't count)" (Lloyd, 2008: 103). This power operates through a self whose being "is dependent, not just on the existence of the other in its singularity (as Levinas would have it), but also on the social dimension of normativity that governs the scene of recognition" (Butler, 2005: 23). Hetero- and cisnormativity are such dimensions.

At stake are two distinct modes of alterity. The first, aligned with hetero- and cisnormativity, is where the LGBT other is cast as abnormal, marginalized and subject to discrimination. The second is where the other is regarded as unique, irreplaceable and deserving of respect and devotion (Rhodes and Westwood, 2016). Butler's (2004) reading of Levinas alerts us to it is how this latter meaning is centrally related to a politics of de/humanization. If the other's difference from what is taken as the norm is used as the basis for discrimination in the context of oppressive social values, then that other is effaced and dehumanized. Conversely, if the other is approached in terms of their infinite uniqueness, and responded to with genuine care and respect, then alterity is a prompt to humanization and, in Levinas' term, ethics. The specific character of LGBT as a category conceived through alterity thus renders an ethics of LGBT diversity conceivable in relation to Butler's account of humanization. Discrimination against a person not conforming to hetero- or cisnormativity is a force that would rob them of any right to be treated as an ethical other. If, following Levinas, we are awakened to ethics by difference, awakened by the other, then the normalizing discourse Butler refers to serves to categorize certain people as not deserving of such ethical attention. Butler gives the example of how the "queer lives that vanished on September 11 are not publicly welcomed into the idea of national identity currently being built in the obituary pages"such that "humanization takes place differently through variable norms of recognition" (Butler, 2003: 23 and 30).

For Levinas ethics is "the calling into question of my spontaneity by the presence of the other" (1969: 43). By spontaneity Levinas refers to one's sense of completeness as an individual who uses freedom to pursue one's own self-centred goals. Spontaneity is a "joyous possession of the world" (1969: 76) for oneself and one's own gratification. Ethics, in this arrangement, is that which questions one's own freedom and demands that engagement with the world for one's own ends is always open to question by the other person. With spontaneity the other is just a part of the world that is at my disposal. Spontaneity is hence a sense of "autonomy to the point of internalizing or comprehending exteriority, placing the other in a closed context of meaning" (Nelson et al 2005: 121). Ethics, in contrast, is a thorough questioning of the primacy of the ego in the name of the other; it interrupts the very formation of self and its interests. Levinas' ethics evinces a 'humanism of the other' (2003); one not emanating from the self and its righteousness, but originating in the other person and one's ethical obligation to that other. This is an other that appears as a 'face' (rather than as a category such as LGBT): a unique and incomparable other who reminds us that we are not alone in our self-absorption, and that we are indebted to the other for our very existence. 
Butler and Levinas' account of ethics, as canvassed so far, serves us well in explaining the ethical critique of the business case for LGBT diversity. This is so in that the business case is castigated in terms of its primary drive for organizational self-interest. The actions arising from self-justified organizational rationality are of course not identical to Levinas' account of spontaneity. The two do, however, resonate in how corporate action on diversity can be understood as a variation of a "solitary freedom that does not put itself into question" (1969: 304) but rather maintains the solidity and primacy of its hetero- and cisnormative self-interest as can be accomplished through its categorization of otherness. Following Butler, it is this categorization that produces a discourse of social norms that creates and perpetuates discrimination. Notably, the corporation is clearly not a person who is acting in the world. Actions are taken in its name by people whose own sense of who they are is wrapped up in an identification with the hetero- and cisnormative character of the corporate person that is notionally able to pursue what are construed as its own interests. It is on the basis of this corollary that the business case for LGBT diversity can be described as an affront to a 'moral imperative' rested on the illusion that "there is a continuous match between business needs and the rights and needs of disadvantaged groups" (Jonsen et al, 2013: 276). Conversely the argument for the social justice case would claim that ethics would drive business to question its own spontaneously accepted idea of its self and its hetero- and cisnormative legacy so as to be interrupted by its responsibility for LGBT others; to yield to its responsibility for the sake of ethics itself by bringing its own hetero- and cisnormative identity into question.

\section{Justice, Politics and Praxis After Spontaneity and Ethics}

While the discussion so far goes some way in understanding the impetus behind a moral critique of the business case approach, care needs to be taken not to stop here. While Levinas distinguishes between ethics and spontaneity, this serves to understand the very ethics of ethics itself, rather than to proclaim it as a normative or evaluative practice. The purpose in doing so "does not consist in constructing ethics [...but only to...] find its meaning" (Levinas, 1985: 90). Levinas' ethics, taken alone, does not set out any specific or prescriptive ethics; it explores the more fundamental sense of the ethical that would lie beneath any such system. Because of this, while Levinas' ethics might be drawn on to inform an understanding of the ethics of LGBT diversity, it is not adequate to inform its practice. That is to say it is not a praxis because it does not lend itself alone to political action and its justification. Levinas offers an ethics described in what can appear as idealistic terms, elaborating how ethics is revealed in the face of the other such that we are awakened from selfish slumber and come to realised our ethical subservience to that other. Levinas even goes so far as to state that the ethical subject is a hostage to the other, persecuted by the other, and always willing to sacrifice itself for the other (Levinas, 1998). Acknowledging this, the practical implications of Levinas' ethics emerge through the consideration of the passage from the meaning of ethics, to the practicalities of politics (Butler, 2014) and justice in the social world (Critchley, 1992). This Levinasian 'ethico-politics' (Fagan, 2013) provides us with a counterpoint to the spontaneity of the business case and the ethics of the social justice case noted above. This is so, because ethical praxis exceeds the simple demands of 'good conscience' and comes to embody "the exigency to rebel against injustice committed against the other" (TahmasebiBirgani, 2014: 12). Aligned with Butler's position, there is a continuity between ethics and politics, such that "political struggles against the norm are a way of securing the possibility of ethical relations" (Lloyd, 2007:155)

For Levinas, justice is called forth in response to the practical problems of enacting the excessive demands of ethics. Indeed, if a notion of ethics based on the sanctity of and 
responsibility towards the other person is accepted, what happens when one is called to responsibility for more than one person? This is what Levinas calls the entry of the 'third party' who divides one's ethical attention between multiple others. It is in this sense that while justice can be regarded as the impossible but necessary task of distributing one's care, duty and resources between people, each of whom is unique and incomparable as well as deserving (Levinas, 1974). In posing the question 'how is it there is justice?', Levinas (1985) responds:

It is the fact of the multiplicity of men [sic] and the presence of someone else next to the Other, which condition the laws and establish justice. If I am alone with the Other, I owe him everything; but there is someone else. Do I know what my neighbor is in relation to someone else? Do I know if someone else has an understanding with him or his victim? Who is my neighbor? It is consequently necessary to weigh, to think, to judge, in comparing the incomparable. The interpersonal relation I establish with the Other, I must also establish with other men; it is thus a necessity to moderate this privilege of the Other; from whence comes justice. Justice, exercised through institutions, which are inevitable, must always be held in check by the initial interpersonal relation. (pp. 89-90)

Justice is about how ethics manifests in the social and institutionalized world of interpersonal relations. Moreover, as Butler (2014) explains, with justice we enter the realm of the political; a realm that inevitably involves a "deformation of the ethical" while at the same time being unrefusable if ethics is to bear on social practice (p. 55). While it is an ethical desire for and service to the other that inaugurates the need for justice, justice demands rules and rationality so as to decide and justify how things might be divided between all of the others. It also requires political intervention that will counter injustice as it arises, using the practical means that are at one's disposal. Resting on either moral self-conviction or subsumption to one other is not enough if justice is the goal. In relation to organizations, what emerges is that the task of justice concerns the very nature of the exercise of, and resistance to, organizational power if that power is to be exercised in a manner that places ethics prior to it (Byers and Rhodes, 2007). Justice is the imperfect social implication of ethics.

With this idea of justice ethics (manifested for our purposes here in the social justice case for LGBT diversity) becomes yoked to politics in that while "ethics is fundamental" it is also the case that this means that "politics and political justice are necessary" (Morgan, 2011: 109). The question for LGBT diversity is not just about whether or not it is righteous in its demands for ethical recognition, but also about what political actions can be taken so as to respond positively to that demand. The necessity of politics is such that ethics, if it is to be meaningful in communal life, must yield to political action that seeks justice. Ethics and politics are connected in an inseparable praxis (Fagan, 2013) whereby "politics intervenes to put a stop to interpersonal and intra-group violence" (Bergo, 1999: 253). Striving for equality in the workplace is an example of such a political intervention in response to the spontaneity enacted in the name of organizational self-interest. It is here that business and justice cases for diversity interact rather than being conceived as separated by the ideational chasm between spontaneity and ethics. If political action is to be taken in organizations then the business case, as the dominant mode of the cultural logic of business, is an unavoidable part of that reality. This does not mean subsuming the demand for justice to business logic, but rather acknowledging that a politics that seeks justice cannot ignore it or wish it away with high minded thoughts of ethics and responsibility. 
For Levinas and for Butler, the political pursuit of justice is necessitated by ethics, but is always ethically compromised. The purity of ethics, realised in the selfless devotion and responsibility to the one other, must always be divided and diluted in the face of the demands of all of the other others. Politics in this sense is an ethical praxis that, while never forgetting its origin in ethics, must engage in the practical realities of life in order for justice to be pursued. The question for LGBT diversity based on a demand for justice, is not one that can reside on the righteous moral ground that distances itself from business and its cases in order to maintain the moralism of its own position. The business case for LGBT diversity is of course an example of politics playing out in organizations; one that exemplifies calls for justice and equality have been reformulated within an overriding business logic. It is a politics that has lost sight of the demand for justice that inaugurated it; reduced it to yet another vehicle for self-interested, myopic and autistic spontaneity. In responding to this, an ethical praxis for diversity does not dismiss the business case tout court from a moral high ground, but works both with and against it, using its logic for purposes of its own ethically inspired project. If anything the presence of the business case is a fissure in the long standing wall of hetero- and cisnormative discrimination. This does not mean disciplining oneself to the logic of business; it is about using the resources at hand to act out a politics whose justification is to resist and oppose those who "ignore the responsibility for the other" (Simmons, 1999: 98). That is, to oppose those organizations that ignore their responsibility to the LGBT other that they themselves have cast in their hetero- and cisnormative shadow. Might then the existence of the business case offer an opportunity rather than a threat to the possibilities for LGBT social justice? Might it not be something to be deployed politically for the sake of justice, rather than merely being castigated as justice's unrighteous other? Might it not be something that can be politically employed for purposes beyond its own selfjustification? Can a politics of diversity that uses and engages with the business case still retain the principle that justice and politics must never forget their origin in ethics?

\section{Praxis, Ethics and Politics}

The distinction between the business and social justice cases for diversity has already been brought into question in diversity research where it is argued that a reconciliation can be found through organizational initiatives that "effectively combine performance with an affirmation of the value of the diverse other" (Gotsis and Kortzi, 2013: 948; Dijk et al, 2012; Maxwell, 2004; Swan and Fox, 2010). This would be so when managers "support implementation of diversity management by both business-case arguments and by socialjustice arguments" (Bleijenbergh et al, 2010) so as to "to obtain both equality and business success" (Kamp and Hagedorn-Rasmussen, 2004: 522). The results is a "dual agenda, meant to simultaneously foster the attainment of both the organization's strategic goals and social justice by advancing the individual development and inclusion of all members of the organization" (Heres and Benschop, 2010). How balanced this agenda can be has, however, been brought into critical question. An affirmative answer as to whether organizations "will, or can, take the leap of faith necessary to give sufficient space to justice reasons for valuing diversity" has been judged as unlikely given "the extent that workplaces are constructed around the achievement of business or organizational goals" (Barnes and Ashtiany, 2003:293). In practice it is clear that organizations adopt LGBTI-friendly policies for a variety of reasons that are not ethical in orientation. These include conforming to socially constructed standards within the human resource management profession, compliance with anti-discrimination laws, and competing with business rivals who have implemented such policies (Newbury, Gardber, Hudson and Pfeffer, 2015). 
Following the discussion of ethics and politics that has been evinced here, even if the hopefulness of the dual agenda approach was possible it is still ethically inadequate. Seeking to reconcile corporate self-interest with the pursuit the ethical demands of the other puts ethics and self-interest on equal grounds. Following Levinas, however, justice must always be preceded by and subordinated to the ethics of the other. The other is the only ethical authority. What has been called here ethical praxis differs from the dual agenda approach in that rather than seeking reconciliation with commercial interests, for justice to be meaningful on its the terms of its own origin, those interests must always be subordinated to ethical basis of that justice. This does not mean taking the high moral ground where business cases are to be wholly rejected (Tomlinson and Schwabenand, 2010) and social justice cases put on a pedestal of ethical idealism (Colgan and McKearney, 2012). Indeed, narrowing down diversity "into the varieties of pure social activists versus co-opted management" is not necessarily helpful to the realities of political practice (Swan and Fox, 2010: 571).

Accordingly, the 'praxis' in ethical praxis means that pursuing the ethics of LGBT equality involves engaging in a politics of change that uses the resources at hand to aid that pursuit. Moreover, while the rhetoric that creates the distinction between the business case and the social justice case fails to account for or acknowledge this politics, existing research into diversity practice both demonstrates and exemplifies how diversity activists are actually engaging in it. A central part of this politics involves exploring how the existence of the business case can be strategically used to pursue ethically informed justice, without succumbing its self-oriented logic.

Established patterns of hetero- and cisnormative discrimination can clearly lead to LGBT people having less power, less access to resources, less influence over others, and less ability to advance to positions of power and prestige (Herek, 2007; Link and Phelen, 2001). Against this, diversity activism and management harbor the potential to create sites of resistance where "the 'business case' rhetoric of 'workplace diversity' can act like a Trojan horse: on the outside are the HRM [business case] arguments, on the inside is a passion for justice and, for the marginalized, a drive for empowerment" (Jones and Stablein, 2005:160). This involves not only LGBT employees and their allies joining to 'rebel against injustice' (see Tahmasebi-Birgani, 2014), but also recognizes that the business case provides a resource with which diversity can be sought through acts of resistance, rather than being simply dismissed on account of its manifest ethical poverty. It is the rhetoric of the business case that is a cleft through which action for the primary goal of social justice can be taken.

It has been noted that the idea of 'managing diversity' focusses attention away from activism directed at equality for marginalised groups, and towards commercial and managerial agendas (Benschop, 2001). The danger is that diversity becomes a managerial tool rather than harbinger of social justice. Countering this, however, does not mean abstaining from understanding or exploiting business logic. This is practically accounted for in that "while practitioners might use the business case model when appealing to senior managers, they also tend to define diversity with a social justice framework for themselves" (Ahmed, 2007: 241). While diversity management has been framed largely in relation to its business benefits, it is not a singular or homogenous discourse guided by just one motive. Despite the managerial centre of diversity management, there remains embedded in it the strong trace of social justice. This rings true even for those employed in organizations to promote diversity, in that while they "are supposed to be committed to the business case for diversity management that their organizations have employed [...] they commonly have a wider personal vision of organizational change and development, including transforming inequalities, with an 
objective of social justice" (Tatli et al, 2015: 1247). It is this use of the business case for the primary purpose of redressing inequality that exemplifies ethical praxis.

Accepting that the business case can be moblilized for the purpose of justice "leads to developing initiatives to counter inequality or discrimination while practising diversity management" (Kamp and Hagedorn-Rasmussen, 2004: 535) such that "playing the game is not simply a matter of deciding to be in or out, or choosing to sell out or keep pure" (Swan and Fox, 2010: 586). With ethical praxis business discourses related to diversity are used strategically (Tatli et al, 2015) and without fidelity to their own commercial logics. The question this infers is not so much about whether managerially oriented approaches to diversity are morally justifiable, but rather about whether they can be used to "assist in the realisation of greater workplace equality" (Barnes and Ashtiany, 2003: 275). This is a question of ethical praxis; a question of what can be done, given the situation one is in, to pursue justice in the name of ethics. A good example of this comes in the form of employerrecognized LGBT employee groups established to "offer a space for social support and provide an organized platform from which employees can advocate for changes within their workplaces" (Githens and Aragon, 2009: 121). The significant expansion of such groups in recent years marks a particular and effective means through which justice has been pursued and achieved by and for LGBT employees. Such employee groups engage with organizations in terms of asserting how supporting their objectives is a means for the organizations themselves to better achieve their goals. Despite this, it has been noted that those involved continue to identify as activists and that they "often frame equity and fairness issues in business terms, though their primary motivations are usually much larger than the goal of increasing corporate profit or improving organizational effectiveness" (p. 127). Another example is the use of formal metrics, such as the Stonewall Equality Index, as a means through which organizations measure sexual diversity. While such metrics are positioned as a source of competitive advantage, it has been noted that their existence means that "engaging in a business case discourse occasions opportunities for LGBT organizations to connect with companies using a language they understand" (Rumens, 2014: 189).

Ethical praxis might be considered as the domain of 'tempered radicals': those "individuals who identify with and are committed to their organizations, and are also committed to a cause, community, or ideology that is fundamentally different from, and possibly at odds with the dominant culture of their organization" (Meyerson and Scully, 1995: 585). With ethical praxis, however, the pursuit of justice is not so much located in an ambivalent identity. Instead the dominant 'business case logic' of organizations is used strategically and without subsumption to it- ethical praxis is only in-between justice and business to the extent that justice is on top as the superordinate priority. Without this there is always the threat that what began as political activism for the rights of LGBT people and other classified as 'diverse', that is rights that have been historically denied by work organizations, can become incorporated into a corporate ideology enamoured by manipulating diversity for its own ends (Ward, 2008). Diversity management and its business case are by now well institutionalized within management thinking and practice (Kirby and Harter, 2001; Edelman, Fuller and Mara-Drita, 2001). While this institutionalization is more prevalent for gender and racial diversity, its driving logic of the business case is dominant across the general practice of diversity management. It is by exploiting this logic for the case of justice in the workplace that ethical praxis is enacted in a way that is not stymied by idealistic demarcations between business and social justice arguments. The Trojan horse of the business case (Jones and Stablein, 2005) acts as a means through which justice can be achieved. Employing this might mean resigning one's ethical idealism, but it is a pragmatic choice that involves privileging 
the benefits of real improvements in justice, equality and diversity over the high moral ground that would divorce diversity politics and activism from an engagement with the internal dynamics of business.

\section{Conclusion}

LGBT, as a classification relevant to workplace diversity, is an acronym whose identity is formed in opposition to the hetero- and cisnormative cultures that have long infused organizations. Moreover, the workplace issues facing individuals who might variously be identified with, or identify as, lesbian, gay, bisexual, or transgender are far from consistent in nature or intensity. The same is true for the actual and possible political responses to those issues. Despite these differences LGBT, and its various correlates, has emerged as a political category that is central to workplace equality and diversity. Within this politics it is demonstrably the case that the distinction between the business case and the social justice case have formed a central distinction in how the motives for the pursuit of LGBT diversity have been formulated, as is indeed the case with diversity more generally. What has been argued in this paper is that this division, when looked at from the perspective ethical praxis, is neither as stable nor as useful as it might at first seem. This instability has opened political possibilities in that, irrespective of its motives, the institutionalization of a business case logic for diversity in organizations has allowed people to actively respond to ethical demands for diversity. Such a response uses the rhetoric of the business case for purposes for which it was not designed; that is for ethically motivated purposes. What this heralds is a politically motivated ethical resistance (Pullen and Rhodes, 2014) that turns the language of business back on itself for the sake of non-business related motives. While this does not redeem the ethics of organizations at the level of managerial practice, it does show how ethical praxis can be put in play despite that practice while still having to operate within the powerful cultural context that such practice creates.

While others have hoped for a 'dual agenda' where diversity can lead to both business and social justice outcomes, in practice there is a likelihood that such an agenda will also mean social justice being constantly subservient to profit (Jones and Stablein, 2005). Railing against this, the contribution offered in the paper has been to demonstrate how ethical praxis can be deployed both despite and because of non-ethically motivated approaches to diversity in business. It has been asserted that critiques of the business case for diversity rely on a pure ethics that does not recognize the complexity of its connection to politics. Concurrently it has been acknowledged that the support for the business case evinces a politics that has failed to remember its origin in ethics. Ethical praxis has been positioned as a way out of the stalemate of such positions. Already exemplified in the concrete interventions of activists, this praxis is deserving of attention too by researchers. Such inquiries would continue to investigate how the business case for diversity, albeit justified on the grounds of organizational self-interest, can and has also been used to create real possibilities for justice in organizations. This would also show how political resources are being employed to achieve real improvements in justice, all the time never forgetting their origin in ethics.

\section{References}

Ahmed, S. (2007) The Language of Diversity, Ethnic and Racial Studies 30(2): 235-56.

Ahonen, P., Tienari, J., Meriläinen, S., and Pullen, A. (2014). Hidden contexts and invisible power relations: A Foucauldian reading of diversity research. Human Relations, 67(3), 263286. 
Barnes, L. and Ashtiany, S. (2003) 'The Diversity Approach to Achieving Equality: Problems and Pitfalls', International Law Journal 32(4): 274-96.

Bendl, R., Fleischmann, A., and Walenta, C. (2008). Diversity management discourse meets queer theory. Gender in Management: An International Journal, 23(6), 382-394.

Bendl, R., and Hofmann, R. (2015). Queer Perspectives Fuelling Diversity Management Discourse. In R. Bendl, I. Bleijenbergh, E. Henttonen and A.J. Mills (Eds.) The Oxford Handbook of Diversity in Organizations, pp. 195. Oxford: Oxford University Press.234.

Bergo, B. G. (1999). Levinas between ethics and politics: For the beauty that adorns the earth. Dordrecht: Kluwer Academic Publishers.

Berlant, L., and Warner, M. (1998). Sex in public. Critical Inquiry, 24(2), 547-566.

Bleijenbergh, I., Peters, P., and Poutsma, E. (2010). Diversity management beyond the business case. Equality, Diversity and Inclusion: An International Journal, 29(5), 413-421.

Braithwaite, J. P. (2010). Diversity Staff and the Dynamics of Diversity Policy-Making in Large Law Firms. Legal Ethics, 13(2), 141-163.

Butler, J. (1990). Gender Trouble: Feminism and the Subversion of Identity. London: Routledge.

Butler, J. (2003). Violence, mourning, politics. Studies in Gender and Sexuality, 4(1), 9-37.

Butler, J. (2004). Precarious life: The powers of mourning and violence. London: Verso.

Butler, J. (2005). Giving an account of oneself. Oxford University Press.

Butler, J. (2013). Parting ways: Jewishness and the critique of Zionism. New York: Columbia University Press.

Byers, D., and Rhodes, C. (2007). Ethics, alterity, and organizational justice. Business Ethics: A European Review, 16(3), 239-250.

Chambers, S. A. (2007). 'An Incalculable Effect': Subversions of Heteronormativity. Political Studies, 55(3), 656-679.

Chambers, S.A. and Carver, T. (2008) Judith Butler and Political Theory, London: Routledge.

Chung, Y. B. (2003). Ethical and Professional Issues in Career Assessment With Lesbian, Gay, and Bisexual Persons. Journal of Career Assessment, 11(1), 96-112.

Colgan, F. (2011). Equality, diversity and corporate responsibility. Equality, Diversity and Inclusion: An International Journal, 30(8), 719-734.

Colgan, F. (2016). LGBT Company Network Groups in the UK: Tackling Opportunities and Complexities in the Workplace. In T. Kollen (Ed.) Sexual Orientation and Transgender Issues in Organizations, pp. 525-538, Heidelberg:Springer.

Colgan, F., and McKearney, A. (2012). Visibility and voice in organisations: Lesbian, gay, bisexual and transgendered employee networks. Equality, Diversity and Inclusion: An International Journal, 31(4), 359-378.

Colgan, F., and Rumens, N. (2014) Understanding sexual orientation at work." In F. Colgan and N. Rumens (Eds) Sexual orientation at work: Contemporary issues and perspectives, $\mathrm{p}$. 1-20, London: Routeldge. 
Colgan, F., Wright, T., Creegan, C., and McKearney, A. (2009). Equality and diversity in the public services: moving forward on lesbian, gay and bisexual equality? Human Resource Management Journal, 19(3), 280-301.

Cragg, W. (2015). The profit maximization mantra and the challenge of regaining trust, humanity and purpose in an age of crisis. In K. J. Ims and L. J. T. Pedersen (Eds.), Business and the Greater Good: Rethinking Business Ethics in an Age of Crisis (pp. 41-63). Cheltenham: Edward Elgar.

Cunningham, G. B. (2011a). Creative Work Environments in Sport Organizations: The Influence of Sexual Orientation Diversity and Commitment to Diversity. Journal of Homosexuality, 58(8), 1041-1057.

Cunningham, G. B. (2011b). The LGBT advantage: Examining the relationship among sexual orientation diversity, diversity strategy, and performance. Sport Management Review, 14(4), 453-461.

Edelman, L. B., Fuller, S. R., and Mara-Drita, I. (2001). Diversity Rhetoric and the Managerialization of Law. American Journal of Sociology, 106(6), 1589-1641.

Fagan, M. (2013) Ethics and politics after poststructuralism: Levinas, Derrida and Nancy. Edinburgh: Edinburgh University Press.

Foldy, E. G., and Creed, W. E. D. (1999). Action Learning, Fragmentation, and the Interaction of Single-, Double-, and Triple-Loop Change A Case of Gay and Lesbian Workplace Advocacy. The Journal of Applied Behavioral Science, 35(2), 207-227.

Githens, R. P., and Aragon, S. R. (2009). LGBT Employee Groups: Goals and Organizational Structures. Advances in Developing Human Resources, 11(1), 121-135.

Gotsis, G., and Kortezi, Z. (2013). Ethical paradigms as potential foundations of diversity management initiatives in business organizations. Journal of Organizational Change Management, 26(6), 948-976.

Healy, G., Bradley, H., and Forson, C. (2011). Intersectional sensibilities in analysing inequality regimes in public sector organizations. Gender, Work and Organization, 18(5), 467-487.

Herek, G. M. (2007). Confronting Sexual Stigma and Prejudice: Theory and Practice. Journal of Social Issues, 63(4), 905-925.

Heres, L., and Benschop, Y. (2010). Taming diversity: an exploratory study on the travel of a management fashion. Equality, Diversity and Inclusion: An International Journal, 29(5), 436-457.

Herring, C., and Henderson, L. (2014). Diversity in Organizations: A Critical Examination. New York: Routledge.

Humphrey, J. C. (1999) Organizing sexualities, organized inequalities: Lesbians and gay men in public service occupations. 6(3): 134-151.

Jones, D., and Stablein, R. (2005). Diversity as Resistance and Recuperation: Critical Theory, Post-Structuralist Perspectives and Workplace Diversity. In A. M. Konrad, P. Prasad, and J. Pringle (Eds.), Handbook of Workplace Diversity (pp. 145-166). London: SAGE.

Jonsen, K., Tatli, A., Özbilgin, M. F., and Bell, M. P. (2013). The tragedy of the uncommons: Reframing workforce diversity. Human Relations, 66(2), 271-294. 
Kamp, A., and Hagedorn-Rasmussen, P. (2004). Diversity management in a Danish context: towards a multicultural or segregated working life?. Economic and Industrial Democracy, 25(4), 525-554.

King, E. B., and Cortina, J. M. (2010). The Social and Economic Imperative of Lesbian, Gay, Bisexual, and Transgendered Supportive Organizational Policies. Industrial and Organizational Psychology, 3(1), 69-78.

Kirby, E. L., and Harter, L. M. (2001). Discourses of diversity and the quality of work life. Management Communication Quarterly, 15(1), 121-127.

Kirton, G., and Greene, A. M. (2009). The costs and opportunities of doing diversity work in mainstream organisations. Human Resource Management Journal, 19(2), 159-175.

Knights, D., and Omanović, V. (2016). (Mis)managing diversity: Exploring the dangers of diversity management orthodoxy. Equality, Diversity and Inclusion: An International Journal, 35(1): 5-16..

Konrad, A. M. (2003). Defining The Domain Of Workplace Diversity Scholarship. Group and Organization Management, 28(1), 4-17.

Levinas, E. (1969). Totality and infinity. Pittsburgh: Duquesne University Press.

Levinas, E. (1974). Otherwise Than Being or Beyond Essence. Pittsburgh: Duquesne University Press.

Levinas, E. (2003). Humanism of the other. Urbana: University of Illinois Press.

Levinas, E., (1985). Ethics and Infinity: Conversations with Philippe Nemo. Pittsburgh: Duquesne University Press.

Link, B. G., and Phelen, J. C. (2001). Conceptualizing Stigma. Annual Review of Sociology, 27, 363-385.

Lloyd, M. (2007). Judith Butler: From norms to politics. Cambridge: Polity.

Lloyd, M. (2008) Towards a Cultural Politics of Vulnerability: Precarious Lives and Ungrievable Deaths, in T. Carver and S.A. Chambers (Eds.) Judith Butler's Precarious Politics, pp. 92-106, New York: Routeldge.

Lorbiecki, A., and Jack, G. (2000). Critical Turns in the Evolution of Diversity Management. British Journal of Management, 11, S17-S31.

Marcus, P. (2010). In Search of the Good Life: Emmanuel Levinas, Psychoanalysis and the Art of Living. London: Karnac Books.

Maxwell, G. A. (2004). Minority report: Taking the initiative in managing diversity at BBC Scotland. Employee Relations, 26(2), 182-202.

Meyerson, D. E., and Scully, M. A. (1995). Crossroads tempered radicalism and the politics of ambivalence and change. Organization Science, 6(5), 585-600.

Michalos, A. C. (2013). The Business Case for Asserting the Business Case for Business Ethics. Journal of Business Ethics, 114, 599-606.

Morgan, M. L. (2011). The Cambridge Introduction to Emmanuel Levinas. Cambridge: Cambridge University Press.

Muhr, S. L. (2008). Othering diversity-a Levinasian analysis of diversity management. International Journal of Management Concepts and Philosophy, 3(2), 176-189. 
Nelson, E. S., Kapust, A., and Still, K. (2005). Addressing Levinas. Evanston: Northwestern University Press.

Newbury, W., Gardberg, N.A., Hudson, B.A. and Feffer, Y (2015) Adoption of LGBTFriendly Policies: Social Construction, Coercion, Competition, or Learning?. Academy of Management Proceedings, 2015(1) 11763.

Ng, E. S., Schweitzer, L., and Lyons, S. T. (2012). Anticipated Discrimination and a Career Choice in Nonprofit A Study of Early Career Lesbian, Gay, Bisexual, Transgendered (LGBT) Job Seekers. Review of Public Personnel Administration, 32(4), 332-352.

Nielsen, R. P. (1993). Organization Ethics from a Perspective of Praxis. Business Ethics Quarterly, 3(2), 131-152.

Özbilgin, M., and Tatli, A. (2011). Mapping out the field of equality and diversity: Rise of individualism and voluntarism. Human Relations, 64(9), 1229-1253.

Ozturk, M. B., and Tatli, A. (2015). Gender identity inclusion in the workplace: broadening diversity management research and practice through the case of transgender employees in the UK. The International Journal of Human Resource Management, ahead-of-print.

Pullen, A., and Rhodes, C. (2014). Corporeal ethics and the politics of resistance in organizations. Organization, 21(6), 782-796.

Raeburn, N. C. Working it out: The emergence and diffusion of the workplace movement for lesbian, gay, and bisexual rights. Authority in contention 25: 187- 230.

Rhodes, C., and Westwood, R. (2016). The Limits of Generosity: Lessons on Ethics, Economy, and Reciprocity in Kafka's The Metamorphosis. Journal of Business Ethics, 133(2), 235-248.

Robinson, G., and Dechant, K. (1997). Building a business case for diversity. The Academy of Management Executive, 11(3), 21-31.

Rumens, N. (2014) Is Your Workplace 'Gay-Friendly'?, in F. Colgan and N. Rumens (Eds.) Sexual Orientation at Work: Contemporary Issues and Perspectives, pp. 181-195. London: Routeldge.

Rumens, N. and Tyler, N. (2015) Towards a Queer Politics and Ethics Within organization Studies, in A. Pullen and C. Rhodes (Eds.) The Routledge Companion to Ethics, Politics and Organizations, pp. 447-461. London: Routledge.

Russell, G. M. (2011). Motives of Heterosexual Allies in Collective Action for Equality. Journal of Social Issues, 67(2), 376-393.Sangganjanavanich, V. F., and Cavazos JR, J. (2010). Workplace aggression: Toward social justice and advocacy in counseling for transgender individuals. Journal of LGBT Issues in Counseling, 4(3-4), 187-201.

Sawyer, K. B., Thoroughgood, C. N., and Cleveland, J. N. (2015). Challenging Heteronormative and Gendered Assumptions in Work-Family Research: An Examination of LGB Identity-Based Work-Family Conflict. In M. J. Mills (Ed.), Gender and the WorkFamily Experience (pp. 77-98). Cham: Springer International Publishing.

Shore, L. M., Chung-Herrera, B. G., Dean, M. A., Ehrhart, K. H., Jung, D. I., Randel, A. E., and Singh, G. (2009). Diversity in organizations: Where are we now and where are we going? Human Resource Management Review, 19(2), 117-133.

Simmons, W. (1999). The Third: Levinas' theoretical move from an-archical ethics to the realm of justice and politics. Philosophy and Social Criticism, 25(6), 83-104. 
Spencer, L. G., and Capuzza, J. C. (2016). Centering Gender Identity and Transgender Lives in Instructional Communication Research. Communication Education, 65(1): 113-117.

Swan, E., and Fox, S. (2010). Playing the Game: Strategies of Resistance and Co-optation in Diversity Work. Gender, Work and Organization, 17(5), 567-589.

Tahmasebi-Birgani, V. (2014). Emmanuel Levinas and the Politics of Non-Violence. Toronto: University of Toronto Press.

Tatli, A. (2011). A Multi-layered Exploration of the Diversity Management Field: Diversity Discourses, Practices and Practitioners in the UK. British Journal of Management, 22(2), $238-253$.

Tatli, A., Nicolopoulou, K., Özbilgin, M., Karatas-Ozkan, M., and Öztürk, M. B. (2015). Questioning impact: interconnection between extra-organizational resources and agency of equality and diversity officers. The International Journal of Human Resource Management, 26(9), 1243-1258.

Tomlinson, F., and Schwabenland, C. (2010). Reconciling Competing Discourses of Diversity? The UK Non-Profit Sector Between Social Justice and the Business Case. Organization, 17(1), 101-121.

Van Dijk, H., van Engen, M., and Paauwe, J. (2012). Reframing the Business Case for Diversity: A Values and Virtues Perspective. Journal of Business Ethics, 111(1), 73-84.

Ward, E.J. (2008) Respectably Queer: Diversity Culture in LGBT Activist Organizations, Nashville: Vanderbilt University press.

Warner, M. (1993). Fear of a Queer Planet: Queer Politics and Social Theory. Minneapolis: University of Minnesota Press.

Yang, Y., and Konrad, A. M. (2011). Understanding Diversity Management Practices: Implications of Institutional Theory and Resource-Based Theory. Group and Organization Management, 36(1), 6-38.

Zanoni, P., Janssens, M., Benschop, Y., and Nkomo, S. (2010). Guest Editorial: Unpacking Diversity, Grasping Inequality: Rethinking Difference Through Critical Perspectives. Organization, 17(1), 9-29. 